\title{
Pulse-Echo Ultrasonic Evaluation of the Integrity of Seams of Single-Ply Roofing
} Membranes: Results of Field Investigations and Recommendations

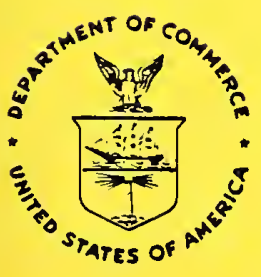

\section{QC}

100

.456

\#4425

1990 $t$ of Commerce

te of Standards and Technology

ling Technology

ID 20899
Prepared for:

Naval Facilities Engineering Command Naval Civil Engineering Laboratory Port Hueneme, CA 93043-5003 



\section{Pulse-Echo Ultrasonic Evaluation of the}

\section{Integrity of Seams of Single-Ply Roofing}

\section{Membranes: Results of Field Investigations}

\section{and Recommendations}

Hiroshi Watanabe*

Walter J. Rossiter, Jr.

"Takenaka Corporation

Technical Research Laboratory

5-14, 2-Chome Minamisuna Koto-Ku

Tokyo, Japan

November 1990

U.S. Department of Commerce

Robert A. Mosbacher, Secretary

National Institute of Standards and Technology

John W. Lyons, Director

Center for Building Technology

Gaithersburg, MD 20899
Prepared for:

Naval Facilities Engineering Command Naval Civil Engineering Laboratory Port Hueneme, CA 93043-5003 

This report describes the second and final phase of a study to develop an ultrasonic NDE method for evaluating the integrity of seams of single-ply roofing membranes. The results of the laboratory evaluation of a prototype pulse-echo apparatus (the field scanner) were positive in that voids could be distinguished from well-bonded sections of the specimen using the intensity of the echo from the adhesive layer. In the phase 2 study, seams of existing EPDM single-ply membranes were examined by roof-top scanning to evaluate the performance of the field scanner in practice. This was followed by laboratory tests to confirm and explain observations made during the field tests of the seams. The field scanner was sensitive to micro-cavities, which could be generated in adhesive layers. This resulted in a number of "false positive" readings. The formation of the micro-cavities was attributed to the temperature-induced volatilization of residual solvent remaining in the adhesive layer after its application on the membrane material. It was concluded that the field scanner technique had Iimited applicability for assessing the condition of solvent-adhesive seams because it could not readily differentiate between the micro-cavities and voids and delaminations in the adhesive layer. The results also implied that the field scanner might be applicable to seams formed using other techniques and that the addition of data recording and processing equipment would enhance the operator's ability to interpret the pulse-echo data obtained.

Key words: adhesive-bonding, EPDM rubber, field inspection, membranes, nondestructive testing, pulse-echo method, roofing, seams, ultrasonics, voids 

Page

ABSTRACT

LIST OF TABLES

LIST OF FIGURES.

1. INTRODUCTION

1.1 Background

1.2 Objective and scope.

2. FIELD SCANNER.

2.1 Description of the Field Scanner . . . . . . . . . 2

2.2 General Measurement Procedure. . . . . . . . . . . 2

3. INVESTIGATIONS OF FIELD SEAM SAMPLES . . . . . . . . . . 4

3.1 The Initial Field Investigation. . . . . . . . . . 4

3.2 Results and Discussions of the Investigations. . . 5

3.2.1 The Roofs Investigated. . . . . . . . . . . 5

3.2.2 Results of Laboratory Tests of Seam Samples 5

3.2.3 Results of Field Inspections Using the

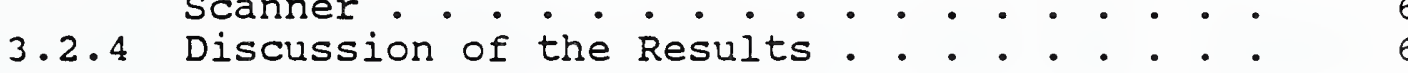

4. INVESTIGATIONS ON MICRO-CAVITY FORMATION . . . . . . . . 9

4.1 Laboratory Experiment on Elevated Cure Temperature 9

4.1.1 Specimen Preparation and Measurement. . . .

4.1.2 Results for the Specimens with Neoprene-

4.1.3 Results for the Specimens with Butyl-Based Adhesive. . . . . . . . . . . 11

4.2 Field Experiment on Elevated Cure Temperature. . . 12

4.2.1 Specimen Preparation and Measurement. . . . 12

4.2.2 Results of the Field Experiment. . . . . . 13

5. COMMENTARY ON THE RESUltS OF THE PHASE 2 STUdY . . . : . 14

6. SUMMARY AND CONCLUSIONS. . . . . . . . . . . . . . 16

7. ACKNOWLEDGEMENTS . . . . . . . . . . . . . . . 18

8. REFERENCES . . . . . . . . . . . . . . . 19

APPENDIX. DESCRIPTION OF THE FIELD SCANNER. . . . . . . . . AI 
Table 1. Summary of roofs investigated. . . . . . . . 20

Table 2. Tests conducted on the laboratory-cured specimens. 21

Table 3. Seam samples and cure conditions . . . . . . . 22

\section{LIST OF FIGURES}

Page

Figure 1. Schematic illustration of echo patterns for a well-bonded section of a seam and a seam section with a void... . . . . . . . . . . . . .

Figure 2. Intensity of EMI echoes measured for seam specimens and single sheets cut from roofs nos. $1-3$.

Figure 3. Intensity of EMI echoes measured in the field investigation for roof nos. 3-5 . . . . . . .

Figure 4. SEM photomicrograph of the ruptured surface of the adhesive layer in seam $A$ of roof no. $3 . . .226$

Figure 5. Results of the laboratory experiment on elevated cure temperature for seam specimens fabricated with a neoprene-based adhesive. . . . . . . .

Figure 6. SEM photomicrograph of the ruptured surface of the neoprene-based adhesive layer. Microcavities are apparent . . . . . . . . . . . .

Figure 7. Results of the laboratory experiment on elevated cure temperature for seam specimens fabricated with a butyl-based adhesive . . . . . . . . .

Figure 8. Temperatures and EMI echo intensity measured for the field seam specimen having a neoprene-based adhesive.

Figure 9. Temperatures and EMI echo intensity measured for the field seam specimen having a butyl-based adhesive.

Figure Al. Prototype field scanner used in the study....

Figure A2. Schematic illustration of the transducer holder acoustically coupled to a seam specimen.... . 


\subsection{Background}

This is the second and final report of a two-phase study to investigate the use of a pulse-echo ultrasonic method to detect voids and delaminations in field seams of single-ply elastomeric membranes. The study was conducted after preliminary investigations $[1,2]$ at the National Institute of standards and Technology (NIST) indicated that the pulse-echo ultrasonic technique offered promise for void detection, but that further research was needed to develop suitable equipment for field use. The results of phase 1 of the present study have been given in a report entitled, "Pulse-Echo Ultrasonic Evaluation of the Integrity of Seams of Single-ply Roofing Membranes: Laboratory Evaluation of a Prototype Test Apparatus" [3].

In Phase 1, a prototype apparatus (called the field scanner) incorporating conventional pulse-echo equipment was developed for inspecting seams of single-ply roofs in service. The prototype was investigated in the laboratory to evaluate variables such as: 1) sensitivity and practical limitations in detecting voids, 2) optimal operating conditions, and 3) influence of the properties of the seam on void detection. It was shown that, in the laboratory, the equipment could effectively maintain acoustic coupling between the transducer and the seam specimens. Two 5-MHz transducers (focusing and non-focusing types) were selected as the most suitable for void detection using the field scanner [3]. Voids incorporated in laboratory seam specimens were readily detected. The results of the Phase 1 investigation provided guidelines on the optimum conditions for use of the field scanner. Encouraging evidence was obtained that, although the apparatus had limitations, NDE testing of seams in service might be accomplished using the field scanner. Thus, phase 2 of the study was conducted to evaluate the use of the field scanner on roofs having single-ply membranes.

\section{2 objective and scope}

This report describes the results of the phase 2 investigations to evaluate the ability of the prototype field scanner to detect voids and delaminations of seams of single-ply elastomeric membranes in service. Adhesive-bonded seams in existing ethylene-propylenediene terpolymer (EPDM) membranes, as well as in roofs under construction, were included in the tests. Laboratory tests were conducted, as necessary, to confirm and explain observations made during the field tests of seams.

Based on the results and conclusions of both the Phase 1 and Phase 2 investigations, recommendations are given on the use of the pulse-echo ultrasonic method for evaluating the integrity of seams of single-ply membranes. 


\subsection{Description of the Field Scanner}

The description of the field scanner designed for inspecting seams of single-ply membranes in the field was given in the Phase 1 report [3]. The Appendix of the present report presents the description for readers who do not have the phase 1 report. The most notable feature of the field scanner is its use of a waterimmersible transducer placed in a plastic holder that has a flexible rubber diaphragm as its bottom surface. A flexible diaphragm was used to provide a conformable surface that could maintain contact with the surfaces of roof membrane seams. The findings of the Phase 1 study showed that, in the laboratory, satisfactory acoustic coupling of the transducer to seam specimens was obtained when an aqueous detergent solution was used as a couplant [3].

\subsection{General Measurement Procedure}

The general measurement procedure used in the field'investigations was based on the operating techniques developed for the field scanner in Phase 1 [3]. Figure 1 illustrates four echoes typically observed for seam specimens when examined using the field scanner. Figure la is for a well-bonded seam which, for purposes of this paper, is one without voids (lack of adhesive) or delaminations. Figure 1b depicts the echo pattern for a seam that contains a void (lack of adhesive) in the adhesive layer. In these figures, the $X$-axis represents relative time and the $Y$-axis represents the relative intensity of the echo. For both the well-bonded seam and the void-containing specimen, the four echoes represent the four interfaces from which the ultrasonic pulses are reflected. These four echoes have been designated as follows (Figure 1):

ED1: Echo from the water-diaphragm interface,

ED2: Echo from the diaphragm-specimen interface, (or in the absence of a specimen, the air-diaphragm interface),

EM1: Echo from the adhesive layer in the seam, (or for a single sheet of membrane material, the echo from the interface of the sheet and its substrate), and

EM2: Echo from the seam specimen-substrate interface.

Note in Figure 1 that the difference between the echo pattern for a well-bonded specimen and that for a specimen with a void. In the former case, the intensity of EMI is relatively low and comparable

1 The upper and lower surface of the adhesive layer in the seam did not show two corresponding echoes. Instead, a single signal having one peak was observed on the oscilloscope. In the following discussion, this reflected signal is named "EMI" and treated as an echo from the adhesive layer. 
to that of EM2. When a void is present, the relative intensity of EMI is high, while that of EM2 is extremely low. In this case, the ultrasonic pulse is mainly reflected at the void in the adhesive. A quantitative measure of peak intensity was needed to analyze and compare the various echo patterns obtained as a function of the variables investigated during the study. To this end, the intensity of an individual echo was increased using the gain controls of the pulse-receiver unit until the peak height reached, but did not exceed, 100 percent of the relative intensity scale on the oscilloscope. The dB value at which maximum peak height was attained was recorded as the intensity of the echo. This technique was used in lieu of equipment that could directly measure echo intensity. Using this technique, the echo intensities were recorded as negative $d B$ values, indicating that the original signals were amplified to reach maximum intensity. The larger the $\mathrm{dB}$ (absolute) value, then the weaker was the intensity of the echo.

It was determined in the laboratory that a sharp increase in the intensity of the EMI echo was observed when the field scanner was pushed over a void in relation to the EMI intensity obtained from well-bonded areas along the seam. Thus, in the field, a sharp increase in the intensity of the EMI echo was to be taken as a qualitative indicator of a void. It was not possible, in the present study, to record the echo intensities while the field scanner was being pushed along seams. To obtain quantitative measurements of the echo intensities, the field scanner was momentarily held stationary while the measurement was made.

Thus, the general procedure used in the field inspections was as follows: 1) adjust the flow rate of the couplant, 2) push the field scanner along the seam while watching the varying echo pattern on the oscilloscope, and 3) stop the field scanner and record the intensities of the four echoes to obtain needed quantitative data.

When conducting the field inspections, a laboratory-prepared control specimen with voids purposely incorporated in the adhesive layer was used on the roof to provide an indication of the echo patterns obtained from well-bonded and void sections of the seam. In addition, during all field inspections, the echo intensities of the single sheet comprising the membrane were recorded for comparison with that of the seam.

In the field, the intensities of the EDI and ED2 echoes were always recorded whenever the intensities of the EM1 and EM2 echoes were determined to check that coupling was adequate. The criteria were based on the phase 1 laboratory results [3]. When coupling was adequate, ED1 was $10 \mathrm{~dB}$ or more stronger than ED2; when coupling was inadequate, ED2 had at least the same intensity as ED1, and was often higher. Thus, for field tests, when (ED2-EDI) was greater than $-6 \mathrm{~dB}$, coupling was considered inadequate and the data for the seams were not recorded. 


\subsection{The Initial Field Investigation}

As the Phase 1 investigations were nearing completion, an opportunity arose to inspect seams of a low-sloped roof in the greater washington, DC area. The roof was waterproofed with an adhered EPDM membrane system, which was reportedly at least 5 years old. The roofing was scheduled for replacement due to problems not associated with the seams. On the contrary, they had reportedly been performing satisfactorily without excessive maintenance.

As an initial investigation, the inspection was conducted qualitatively on the roof without recording echo intensities. However, unexpectedly (in view of the report that the seams were performing satisfactorily), the intensity of the EMI echoes observed as the field scanner was pushed over sections of seams was relatively strong. It was generally comparable to that obtained for the single sheet of the membrane (when measured away from the seam), and indicative of an echo associated with a void or delamination. This observation was not limited to isolated sections of the seam, but consistent across all areas that were inspected.

A small section of a seam was cut from the membrane, delaminated from the insulation below, reset on the roof, and re-inspected using the field scanner. The observed echoes were again indicative of voids or delaminations in the specimen. The seam specimen was manually delaminated to expose an adhesive layer that was bonded and without voids. The finding was called a "false positive." As a result, the initial inspection was ended, because the "false positive" needed to be explained. Another seam specimen was cut from the roof and returned to the laboratory for further analysis.

The consequence of the initial field inspection was a re-design of the planned approach to evaluating the field scanner on roofs. The number of field inspections was reduced, while the extent of laboratory and simulated field testing was to be increased. These two activities were conducted concurrently. The following two sections of the report describe the results of the limited number of field inspections and laboratory tests, respectively.

The findings of the initial field inspection were not an isolated event. Other roofs gave "false positives." The laboratory testing, as will be detailed in section 4.1, indicated that the "false positives" were associated with the formation of microcavities $^{2}$ (or small bubbles) in the adhesive layer at the time of seam fabrication in the field.

"The word, "micro-cavity" is used to express the size of very small voids (about $20 \mu \mathrm{m}$ in diameter) in the adhesive layers in the seam specimens. Note that the intent of the present study is to detect the absence of adhesive (voids) in seams and such defects are much larger in size than the micro-cavities. 


\subsection{Results and Discussions of the Investigations}

3.2.1 The Roofs Investigated. The number of field and related investigations was limited to five roofs, including that of the initial investigation. A 5-MHz focusing transducer [3] was used for these investigations. Table 1 summarizes the five roofs. In each case, the membrane was a non-reinforced EPDM rubber with a nominal thickness of $0.06 \mathrm{in.}(1.5 \mathrm{~mm})$.

Four of the roofs (nos. 1, 2, 4, and 5) ranged in age from 1 to 4 years. Their seams were all reportedly performing satisfactorily by the individuals inviting NIST research staff to perform the NDE inspections. With the exception of roof no. 2, all were inspected on site using the field scanner. None of the visual evidence obtained during the inspections indicated that seam performance had not been satisfactory. In the case of roof no. 2, a seam specimen was sent to the NIST laboratories for analysis with the field scanner.

Roof no. 3 was under construction at the time of the NDE inspection. As a result, the seams inspected ranged from a few minutes to 9 days in age. From observations of the seam fabrication process, the workmanship appeared to be satisfactory. It is noted that the seams constructed during the inspection of roof no. 3 were fabricated shortly after noon on a warm, sunny day when the black EPDM membrane material was noticeably warm to the touch. No information was available concerning the time of year or day when the other roofs were constructed.

A common link between roof nos. 1, 2, and 3 was that seam specimens with a considerable amount of the single sheet of the membrane material intact were sampled. This made it possible to test the seams in the laboratory under controlled conditions, and to examine them to ascertain whether voids or delaminations were present. Another advantage was that the single sheet of the membrane could be examined using the field scanner when the specimen was placed loose-laid on a substrate. This provided assurance that the echo from the single sheet-substrate interface was not influenced by adhesive or water at that location. In this case, the EMI echo from the single-sheet can be considered akin to that from a void in the adhesive layer. It provided an estimate of the intensity expected from the adhesive layer of the seam if a void or delamination were present.

\subsubsection{Results of Laboratory Tests of Seam Samples. Figure 2} presents the results of the laboratory inspections of the seam specimens cut from roof nos. 1, 2, and 3. For all these roofs, there was considerable overlap of the intensities of the EMI echo for the seam specimen with that of the single sheet. Many echoes for the seam specimens were less intense than those of the single sheets. On the other hand, no echoes due to the seam were greater than those of the single sheet.

At first glance, the results in Figure 2 imply that the seam specimens contained some voids or some delaminations. In some 
measurements, not only were the EMI echoes of the seam specimens the same as those of the single sheet, but the intensity values were comparable to those recorded for voids in Phase 1 of the study [3]. For instance, in the laboratory, voids were shown to have EMI echoes ranging from -46 to $-62 \mathrm{~dB}$ [3]. However, delamination of the roof seam specimens in the Phase 2 study showed the adhesive layers to be visually free of voids or delaminations, as was found for roof no. 1 at the time of the initial field investigation.

3.2.3 Results of Field Inspections Using the Scanner. Figure 3 gives the results of the measurements made on roof nos. 3,4, and 5 using the field scanner. In the case of roof no. 3, which was under construction, a number of observations were made of seams that had varying ages. In the case of roof no. 4, a duplicate set of measurements was made with a $5-\mathrm{MHz}$ non-focusing transducer to determine whether a transducer effect was apparent. There was considerable overlap of the intensities of the EMI echoes of the seam specimens with those of the single sheet. As was the case for the laboratory tests, the measurements could be interpreted as indicating some voids and delaminations in the seams. The presence of such defects could not be confirmed or denied in the field because (except for one seam of roof no. 3) cuts were not made. However, there was no reason to believe that voids or delaminations were extensive throughout the seams. In particular, the fabrication of the $20-\mathrm{min}$ and $45-\mathrm{min}$ old seams of roof no. 3 was critically observed without cause for concern that voids were incorporated in the adhesive.

It should be noted, as a reminder, that the data given in Figure 3 represent locations where the field scanner was stationary to allow recording of the echo intensities. The recorded intensities were typical of those observed as the scanner was being pushed across the seam surfaces. It is difficult to believe that the seams would have performed satisfactorily for up to 4 years (e.g., roof no. 4), if they consisted mainly of voids and delaminations. Consequently, the results in Figure 3 were also considered to be generally "false positives."

3.2.4 Discussion of the Results. As part of the investigations to explain the "false positives" observed in the field inspections, peel tests were conducted on the specimen sampled from roof no. 3 . The procedure was the same as that previously described [4] using five 1 by 6 in. (25 by $150 \mathrm{~mm}$ ) strips having a bond length of 4 in. $(100 \mathrm{~mm})$. The specimen had been cured in the laboratory for 4 weeks at ambient conditions before testing. The average strength and standard deviation were 4.7 and $0.7 \mathrm{lbf} / \mathrm{in}$. $(0.82$ and 0.1 $\mathrm{kN} / \mathrm{m})$, respectively. The results were consistent with the visual observations that the seam was bonded without voids or

delaminations in the adhesive. The average peel strength was comparable to those obtained from other field specimens $[5,6]$, but approximately one half that normally obtained in the laboratory. The mode of failure during peel was cohesive, which was typical of seam specimens having butyl-based adhesive applied to cleaned rubber surfaces [7]. Visual examination of the adhesive surfaces 
exposed during the peel testing showed no contaminants present, although some brush marks were visible.

Sections of the delaminated strips were examined using scanning electron microscopy (SEM). A significant feature observed in the SEM analysis was the presence of micro-cavities (small bubbles) in the exposed surface of the adhesive layer. A typical micrograph illustrating the micro-cavities is shown in Figure 4. The diameters of the micro-cavities ranged from about 0.001 to 0.002 in. $(0.03$ to $0.05 \mathrm{~mm})$. They are flaws in the adhesive layer which would be anticipated to cause lower-than-expected peel strengths as compared to specimens without micro-cavities present.

Specimens of roof nos. 1 and 2 were also subjected to SEM analysis. Micro-cavities were also visible in the micrographs.

The presence of micro-cavities in the adhesive layers could explain the "false positives" obtained during the NDE inspections using the field scanner. The acoustic impedance of the neoprene- or butylbased adhesive materials is similar to that of the EPDM membrane material $[3,8]$. This similarity is the reason that ultrasonic pulses are not reflected greatly at the membrane-adhesive interfaces [9]. But the porosity of a material can make its acoustic impedance significantly lower than that of the bulk of the material [9]. This suggests that, when the adhesive layer in the seam is porous, ultrasonic pulses should be reflected at the adhesive-membrane interface because their impedances are no longer similar.

It was hypothesized that the presence of the micro-cavities was due to the temperature-induced volatilization of residual solvent remaining in the adhesive layer after its application on the roofing membrane material. This hypothesis was consistent with laboratory data obtained during previous studies on seam performance $[3,4]$. First, it has been shown that applications of excessively thick layers (about $0.025 \mathrm{in}$. or $0.63 \mathrm{~mm}$ ) of adhesive lead to relatively large cavities in the adhesive layer that can be seen by eye [4]. Such cavities were attributed to solvent entrapment in the thick adhesive layer. Second, attempts ${ }^{3}$ to produce cavity-free layers when the adhesive was excessively thick showed that application of a vacuum to promote solvent volatilization enhanced void formation. Lastly, the Phase 1 results [3] showed that well-bonded adhesive layers, which were excessively thick and thus contained readily visible cavities or bubbles, gave EMI echo intensities reduced in comparison to those obtained from thinner adhesive layers which visually showed no cavities [3].

The fact that well-bonded seams fabricated in the laboratory transmitted the ultrasonic pulse, while at least some of those made in the field did not, was attributed to differences in the environmental conditions at the two locations. In the field, solar

${ }^{3}$ Unpublished results. 
radiation on the black EPDM rubber often heats it to temperatures well above ambient. This might promote volatilization of residual solvent in the adhesive layer. In contrast, in the laboratory where the membrane never experiences solar heating, residual solvent in the adhesive layer could slowly evaporate without producing voids. 
The laboratory investigations were conducted to test the hypothesis that the micro-cavities observed in the adhesive layers of the field seams were caused by solar-heating induced volatilization of the residual solvent remaining in the adhesive layer at the time of bond formation. To verify this hypothesis, the effects of elevated cure temperature on the properties of the adhesive layer were investigated in two experiments: one conducted in the laboratory, and the other performed outdoors. As in Phase 1 of the study, the transducer holder was removed from the field scanner and was set directly on the seam test specimen when the pulse-echo measurements were made.

\subsection{Laboratory Experiment on Elevated Cure Temperature}

Temperatures of black EPDM membranes measured in the field have been as high as $160^{\circ} \mathrm{F}\left(71^{\circ} \mathrm{C}\right)$ or more, depending on the locale, and time of day and year [10]. In the present experiment, seam specimens were prepared at room temperature and split into two groups. The control group was cured at ambient room temperature conditions, whereas the second group (referred to as "heat-cured") was cured in a laboratory oven at $158^{\circ} \mathrm{F}\left(70^{\circ} \mathrm{C}\right)$. Measurements of ultrasonic echo intensities, and adhesive thickness and mass were recorded as a function of cure time. The procedures are given in Table 2. In the case of the heat-cured specimens, they were removed from the oven while the measurements were made. The results for the heat-cured specimens were compared with those for the control specimens.

4.1.1 Specimen Preparation and Measurement. Table 3 presents a summary of the ten seam specimens included in the experiment and the conditions under which they were cured. The size of the specimens was 5 by 6 in. (130 by $150 \mathrm{~mm}$ ) with a 4 -inch (100 $\mathrm{mm}$ ) wide seam centered parallel to the long dimension. The rubber used for specimen preparation was a commercially available, nonreinforced, EPDM roofing membrane sheet having a nominal thickness of $0.060 \mathrm{in}$. ( $1.5 \mathrm{~mm}$ ). The adhesives used for bonding were commercially available, butyl-based and neoprene-based products. They were kept in small, closed containers until use and were thoroughly stirred before application. The procedures for surface cleaning of the rubber sheets, application of the adhesives, and formation of the seam have been previously described [3]. Open times typical of those normally used in the application of adhesives to EPDM roof membrane sheets were employed.

\subsubsection{Results for the Specimens with Neoprene-Based Adhesive.}

Figure 5 gives the results of the echo intensity, adhesive thickness, and adhesive mass measurements made for the seam samples having neoprene-based adhesive. With the exception of cure condition no. 4, all measurements were first made after the specimens had cured for a minimum of 20 minutes at room temperature. Note that for each of the three variables, the initial measurements showed little variation. In the case of the pulse-echo measurements, the initial EMI intensity of approximately 
-80 dB was comparable to that obtained for a well-bonded specimen [3]. Over time, the specimen that was cured at room temperature (condition no. 1) continued to display an EMI echo intensity typical of a well-bonded specimen, although a slight increase above the initial value was observed. In contrast, the specimens subjected to a heat cure within a day of seam formation (condition nos. 2 \& 3) showed a significant jump in the intensity of the EMI echo. The resultant value of -55 to $-60 \mathrm{~dB}$ was typical of an echo from a void or delamination [3].

For the cases where adhesive mass was determined (cure condition nos. 1-3), the specimens showed a loss of mass (due to solvent loss) for at least the first week of cure (Figure 5). The loss was accelerated by the heat cure. The point to be made is that the specimens contained residual volatile solvent when they were subjected to heat-cure condition nos. 2 \& 3 , which produced the marked increase in intensity of the EMI echo. It is evident in Figure 5 that the mass loss from the specimens was tending to a plateau as the cure time approached 4 weeks. It was assumed that the majority of the residual solvent had evaporated from the specimens over this time period. Thus, it was expected that a specimen subjected to a heat cure after most of the solvent evaporated would not show an increase in the intensity of the EMI echo upon heating. Figure 5 includes the EMI echo intensities for the specimen cured at condition no. 4. The EMI echo was essentially unchanged by the heat-cure which was not applied until after a 3-week cure at room temperature.

Figure 5 also includes data on adhesive thickness for the cure condition nos. 1-3. When cured at room temperature, the adhesive thickness decreased as the adhesive lost mass. However, during the times of heat curing, the adhesive layers increased in thickness. This was most noticeable for cure condition no. 2 , where the increase in thickness was about $60 \%$ of the original thickness. This percent increase could not be explained on the basis of normal thermal expansion of the rubber materials upon heating. It was not considered unreasonable to assume that the expansion was due to formation of micro-cavities in the adhesive layer.

At the end of the experiment, the specimens were delaminated manually and visually inspected. In this case, microscopic analysis was not needed to see readily micro-cavities in the adhesive layers of the specimens that showed strong EMI echoes after heat curing (cure condition nos. 2 \& 3). In contrast, those specimens which displayed weak EMI echoes showed no micro-cavities. scanning electron microscopy was conducted, but micro-cavities were only observed in those specimens cured under condition nos. 2 \& 3 . Figure 6 shows a SEM photomicrograph of some micro-cavities.

In summary, the data obtained from the heat cure experiment on seam specimens with neoprene-based adhesive were considered to be consistent with the hypothesis set forth on the mechanism of microcavity formation in adhesive layers. In this experiment, the micro-cavities produced by heating seam specimens when residual solvent was present were large enough to be seen readily by eye. 
It was also shown that, if an adhesive layer cures long enough at a relatively low temperature, it will not be affected by subsequent exposure to elevated temperatures. The long cure at relatively low temperature allows the solvent to evaporate from the seam before subjection to the heat.

4.1.3 Results for the Specimens with Butyl-Based Adhesive. Figure 7 gives the results of the echo intensity, adhesive thickness, and adhesive mass measurements made for the seam samples having butylbased adhesive. The results for the EMI echo intensity

measurements for cure condition nos. 1-4 may be compared with those for the neoprene-based adhesive specimens given in Figure 5. Unlike the results for neoprene-based adhesives, the heat-cure (condition nos. $2 \& 3$ ) of the butyl-based adhesives produced no significant changes in the measured properties of the specimens. It was found for the butyl-based adhesives that no sharp increases in the intensity of the EMI echo were observed after the heat curing.

The implication of these pulse echo measurements was that microcavities were not generated in the adhesive layers. This was found even though the specimens contained residual solvent, as demonstrated by the adhesive mass loss observed over time (Figure 7). Also, consistent with the lack of micro-cavity formation was the observation that no significant increases in the adhesive layer thickness were observed when the specimens were heat-cured. At the end of the 4-week cure period, delamination followed by visual and microscopic examination of the exposed adhesive layers showed no evidence of micro-cavities.

To be sure, the results for cure condition nos. 1-3 were neither consistent with the observed "false positives" observed in the field NDE inspections of butyl-based seams nor the hypothesis for the formation of micro-cavities as the explanation of the "false positives." In re-thinking the experiment conducted on the butylbased adhesives, it was considered that a major difference existed between the laboratory procedure and an adhesive application process that may occur in the field. In the field, the EPDM rubber may sometimes already be hot (due to solar radiation) when the adhesive is applied. In the laboratory experiments, the adhesive application was performed at room temperature and the specimens remained at that temperature for a minimum of 20 minutes before the heating.

Consequently, an additional experiment (cure condition nos. 5 \& 6) was conducted on specimens with butyl-based adhesive. The rubber was either at room temperature or pre-heated when the adhesive was applied. After seam formation, in both cases, the specimens were immediately placed in an oven for curing at the elevated temperature.

The results of the pulse echo measurements for the cure condition nos. 5 \& 6 are given in Figure 7 along with the data previously discussed. It was found that, when the adhesive was applied to the rubber at room temperature, the immediate determination of the 
intensity of the EMI echo was akin to that of a well-bonded specimen. However, after 20 minutes of heat-cure, the EM1 intensity displayed a sharp increase and was typical of a void in the adhesive layer. When the adhesive was applied to heated rubber (cure condition no. 6), the intensity of the EMI echo measured immediately upon seam formation was typical of that produced by a void in the adhesive layer. The observations for cure conditions 5 \& 6 were consistent with the formation of micro-cavities due to expansion of residual solvent in the adhesive layer. SEM analyses of the delaminated specimens at the end of the cure period showed micro-cavities to be present.

The findings for the elevated temperature cure of the butyl-based experiments indicated that micro-cavities could be generated if the seam specimens were heat-cured immediately after formation. This was considered consistent with the original hypothesis on the mechanism of micro-cavity formation. It should be noted that the hypothesis did not address the possibility that micro-cavity formation would be prevented by maintaining the newly-formed specimens at a room temperature for a short period of time (e.g., $20 \mathrm{~min}$ ) before application of the heat-cure. Reasons why cure condition nos. 5 \& 6 produced voids, whereas cure condition nos. 2 \& 3 did not, were not investigated. It may have been associated with parameters such as the volatility of the solvent, its solubility in the adhesive, factors affecting nucleation, and the cure of the butyl-based adhesive which is known to increase in strength in time, particularly in the first few hours immediately after application [5].

\subsection{Field Experiment on Elevated Cure Temperature}

As a test of the hypothesis on the formation of micro-cavities, seam specimens were fabricated outdoors on a single, warm, sunny day in June 1990 at the NIST campus at Gaithersburg, MD. The intensity of the EMI echoes for the specimens were recorded as a function of time.

4.2.1 Specimen Preparation and Measurements. Seam specimens were prepared, as in the laboratory experiment, using EPDM rubber membrane sheets and either butyl-based or neoprene-based adhesives. The two specimens were approximately 4 by $2 \mathrm{ft}$ ( 1.2 by $0.6 \mathrm{~m}$ ) with a 4-in. wide $(100 \mathrm{~mm})$ seam at the center parallel to the long dimension. The EPDM sheets were placed on a 2-in. thick (50 mm) expanded polystyrene insulation board $30 \mathrm{~min}$ before the adhesive was applied to their surfaces. After an adequate open time (about 15-20 min), the sheets were joined to form the seams. The specimens were kept in place on the insulation board during subsequent measurements.

The temperatures of ambient air and the surfaces of the EPDM sheets were measured using thermocouples. The intensity of the EMI echoes were measured using the pulse echo equipment placed stationary on three marked locations on each seam specimen. For each point in time, the reported value of the EMI intensity is the average of the 
three measurements. In all cases, the coefficient of variation was $10 \%$ or less.

4.2.2 Results of the Field Experiment. The seam specimens having the neoprene-based and the butyl-based adhesives were formed at 11:00am and 11:30am, respectively. The results of the temperature measurements (Figure $8 \& 9$ ) indicated that both types of specimens cured under the same conditions. In both cases, the surface temperatures of the rubber sheets were above $140^{\circ} \mathrm{F}\left(60^{\circ} \mathrm{C}\right)$ at the time of seam formation and remained above that level for more than $3 \mathrm{~h}$. They reached a maximum of about $150^{\circ} \mathrm{F}\left(65^{\circ} \mathrm{C}\right)$ shortly after 12 noon.

The average values of the EMI echo intensities as a function of time are given in Figures 8 \& 9 for the neoprene-based and butylbased adhesive specimens, respectively. In the case of the neoprene-based specimens, the initial intensity of the EMI echo was $-80 \mathrm{~dB}$. This value increased to $-56 \mathrm{~dB}$ in $2 \mathrm{~h}$, and then remained constant. The butyl-based adhesive specimen showed the same trend as the neoprene-based specimen, but to a lesser degree. In the former case, the intensity at the time of seam formation was -72 dB. It increased to about $-57 \mathrm{~dB}$ in $2 \mathrm{~h}$, and displayed a slight increase over the remaining time of the experiment.

For each type of adhesive, the initial values of the EMI echo intensity were indicative of a well-bonded seam; the subsequent values were typical of echoes from voids or delaminations. Because the specimens were considered to be well made, the interpretation of the data was that micro-cavities had formed in the adhesive layer of the newly-formed seams as they were exposed to the warming solar radiation. This finding was consistent with that from the field inspection of roof no. 3 (Table 1). In the latter case, newly-formed seams, considered to be well made and inspected using the field scanner, showed strong EMI echoes typical of the presence of voids.

In the present field study, a small section of each of the seam specimens was cut for delamination and visual inspection. A close examination revealed that the exposed adhesive layer contained micro-cavities. They were similar to those found in the laboratory experiment using elevated cure temperatures. They could be seen by eye and, therefore, microscopic examination was not conducted. 


\section{COMMENTARY ON THE RESULTS OF THE PHASE 2 STUDY}

Phase 2 of the study was conducted to evaluate the ability of the field scanner to detect voids and delaminations of seams of singleply roofing membranes. The field scanner used the pulse-echo ultrasonic method for evaluating whether hidden discontinuities existed in materials. The field investigations were undertaken after laboratory tests indicated that the field scanner offered promise for this purpose. Unfortunately, as was described in the preceding sections of this report, testing in the field revealed that the method commonly indicated the presence of voids or delaminations in adhesive-bonded seams of EPDM membranes (i.e., "false positives"), even though no large voids or delaminations were present. The "voids" which are of importance in the context of field performance of seams are areas where adhesive is not applied (i.e., skips in the adhesive layer).

The findings of "false positives" should not be interpreted as a failure of the field scanner. On the contrary, the field scanner was doing exactly what it was designed to accomplish -- i.e., to detect discontinuities in the seam system. The unfortunate aspect of the finding is that the pulse-echo method, at least as carried out, could not distinguish between micro-cavities in the adhesive layer and voids (i.e., skips) where adhesive was not applied. It is believed that because of the mechanism of formation of the micro-cavities, they may be prevalent in seams bonded with solventbased adhesives. The cases where they may not be found would include application of adhesives to the rubber substrate under conditions that limit solar heating of the sheets (e.g., cool, cloudy weather).

Inspection of seams formed from solvent-based adhesives may produce a considerable number of readings indicative of voids and delaminations. However, it could not be judged whether such readings would be true or false without extensive cutting of the membrane. This, of course, would defeat the purpose of having the field scanner as an NDE method for seam inspection. Thus, at least in its present form, the field scanner is considered to have limited application for inspecting seams prepared from solventbased adhesives.

The question then arises as to whether the field scanner is applicable to seams fabricated using other techniques. Included here might be methods involving solvent welding (if entrapped solvent does not produce micro-cavities), heat welding (thermal fusion), hot asphalt bonding, and tape bonding. Investigations of the ability of the field scanner to detect voids in seams fabricated using any of these methods was beyond the scope of the present study. However, the experience gained from the limited number of roof-top inspections using the field scanner leads to the belief that the equipment may have applicability in these cases.

In this regard, the findings of the Phase 2 study concerning the practical aspects of using the field scanner on roofs is worthy of comment. When pulse-echo ultrasonics for roof-top seam inspections 
were first considered, the major concern was to design the equipment such that acoustic coupling of the transducer to the seam would be readily maintained during inspections. Although the number of roof-top inspections was limited in the present study, the findings regarding acoustic coupling were generally positive. It was well maintained at most of the locations on the seams inspected using an aqueous detergent solution. In a few instances, coupling was disrupted due to the presence of coarse particles on the seam surface, but lack of coupling in these cases was overcome by brushing the seam.

Also, the equipment was relatively easy to carry to roofs and to set up. For the few scans undertaken, the amount of water used as couplant was not excessive.

A major difficulty in the roof-top operation of the field scanner was that the echo peaks often shifted rapidly back and forth along the time axis of the oscilloscope as the field scanner was moved along a seam. This was attributed to the unevenness of the roof surface, which resulted in varying the distance between the transducer and the adhesive layer. This finding was anticipated from similar results obtained in the Phase 1 study [3]. Nevertheless, it presented a serious complication to interpreting the echo pattern observed on the oscilloscope. To overcome this complication, scanning of the seams had to be performed at a relatively slow pace. Another complication in the field was that the echo patterns on the oscilloscope were difficult to read on bright sunny days. This problem could be overcome by scanning the seams while the head of the inspector and the oscilloscope were wrapped in a shroud. A significant improvement in the field scanner would be the addition of data recording and processing equipment to track shifting echoes and to interpret the results obtained. Under such conditions of operation, the inspector would ideally not have to observe the oscilloscope during the roof scan.

Finally, the possible limitation created by using a focusing transducer in the field scanner is mentioned. It should be remembered that a focusing transducer only scans a narrow area of a seam as it passes over the surface. This could presumably necessitate multiple scans of a single seam to conduct a complete assessment of its condition. However, because of the revised scope of the field study to determine the causes of the observed "false positives," the extent of the limitation due to use of a focusing transducer, and potential methods for overcoming the limitation, were not investigated. 


\section{SUMMARY AND CONCLUSIONS}

This report describes the second and final phase of a study to develop an ultrasonic NDE method for evaluating the integrity of seams of single-ply roofing membranes. Phase 1 of the study developed and evaluated a prototype pulse-echo apparatus (the field scanner), which was designed to scan across seams of roofs while maintaining acoustic coupling to the seam surface. The results of the laboratory examinations were positive in that voids could be distinguished from well-bonded sections of the specimen using the intensity of the echo from the adhesive layer. This echo was relatively weak for well-bonded seams, and relatively strong for voids.

The focus of the investigations in Phase 2 was roof-top scanning of seams to evaluate the performance of the field scanner in practice. seams of roofs with existing EPDM single-ply membranes, as well as those of roofs with EPDM membranes under construction, were examined using the field scanner. Laboratory tests were conducted, as necessary, to confirm and explain observations made during the field tests of the seams.

The following is a summary of the key findings:

Investigations of Field Seams

- When in-service seams fabricated with both neoprene-based and butyl-based adhesives were inspected with the field scanner, the intensity of many echoes from the adhesive layer were indicative of the presence of voids or delaminations. The findings were contrary to experience with the roofs under test in that the seams were reportedly performing satisfactorily or had been observed to be well prepared. Delamination of sections of some of the in-service seams did not show them to contain delaminations or voids (skips) in the adhesive layer. The findings were considered as "false positive" identifications of skips.

- The "false positives" were subsequently attributed to the formation of micro-cavities (small bubbles) in the adhesive layer, which reflected the ultrasonic pulse. It was hypothesized that the micro-cavities were formed due to the temperature-induced volatilization of residual solvent remaining in the adhesive layer at the time of bond formation.

\section{Investigations of Micro-Cavity Formation}

- The findings in these investigations supported the hypothesis. In the laboratory, some seam specimens having either neopreneor butyl-based adhesive were prepared at room temperature and examined using the ultrasonic method. The initial readings of the intensity of the echo associated with the adhesive layer were indicative of well-bonded seams. Depending on the conditions, after curing at $158^{\circ} \mathrm{F}\left(70^{\circ} \mathrm{C}\right)$, some specimens 
subsequently displayed echo intensities indicative of voids. These specimens were shown to be well bonded, and to contain micro-cavities in the adhesive. When the echo pattern was indicative of a well-bonded seam, no micro-cavities were found.

- In the field, seam specimens were prepared on an insulation board on a warm, sunny day. The temperature of the rubber surface exceeded $140^{\circ} \mathrm{F}\left(60^{\circ}\right)$ during the experiment. For both neoprene- and butyl-based adhesive specimens, the intensity of the adhesive layer echo was initially indicative of wellbonded seams. As time passed, the intensity increased to a value indicative of the presence of voids. Again, the specimens were shown to be well bonded, and to contain microcavities or bubbles in the adhesive layers.

Based on results from both the laboratory and field investigations, the following conclusions are made:

1. At least in its present form, the field scanner technique has limited applicability to detecting large voids (skips) and. delaminations in solvent-adhesive seams. The reason is that the field scanner is sufficiently sensitive to micro-cavities or small bubbles that can be created in the adhesive layer at the time of seam fabrication. Unfortunately, the field scanner cannot distinguish between the voids due to lack of adhesive and the micro-cavities. It appears that the microcavities may be prevalent in adhesive-bonded seams of existing roofs as currently fabricated. Consequently, NDE scanning of seams prepared with solvent-based adhesives could produce an extensive number of "false positive" readings.

2. For the limited number of field inspections conducted, the use of the field scanner to inspect seams on roofs was found to be practicable. This implied that the field scanner may have applicability to the inspection of seams formed using other techniques such as solvent welding, heat welding, or tape bonding. An investigation of the use of the field scanner for such seams was beyond the scope of the present study.

3. If the problem regarding "false positive" readings could be overcome, the addition of data recording and processing equipment to the field scanner would enhance the effectiveness of the inspection procedure. 


\section{ACKNOWLEDGEMENTS}

This study was sponsored by the Naval Civil Engineering Laboratory (NCEL), Port Hueneme, California. The authors extend their thanks to Dr. Robert Alumbaugh (NCEL) for his assistance in the development of the study and encouragement throughout. Sincere thanks and appreciation are extended to Christopher Hodges, Darrell Smith, Michael Thompson, and John Van Wagoner for their assistance in conducting the field NDE inspections. Their assistance made possible the evaluation of the field scanner on roofs, and obtaining field samples for laboratory investigation.

The authors appreciated the assistance of their NIST colleagues in conducting the study: James seiler for preparing seam samples, Paul Stutzman for SEM analysis, and James Lechner, Center for Computing and Applied Mathematics, for experimental design and data analysis. The noteworthy comments and suggestions from James clifton, Geoffrey Frohnsdorff, and Larry Masters, who reviewed a draft of this report are also acknowledged with thanks.

Special thanks are expressed to Gerald Blessing, NIST Center for Manufacturing Engineering, who provided valuable assistance in discussing the theory of the ultrasonic pulse-echo method, guidance on conducting measurements, and many useful suggestions on a draft of this report. The authors greatly appreciate the time he spent in many productive meetings with them. 
[1] Rossiter, walter J., Jr., "Investigation of the Use of Nondestructive Methods for Inspection of Seams of Single-Ply Roofing Membranes," NBSIR 86-3455, National Institute of Standards and Technology, Gaithersburg, MD (September 1986).

[2] Rossiter, Walter J., Jr. and Clifton, J.R., "The Use of Nondestructive Methods for Inspection of Single-Ply Roofing Membranes," Durability of Building Materials, 3 (1986), pp. 343-352.

[3] Watanabe, H. and Rossiter, Walter J., Jr., "Nondestructive Evaluation of the Integrity of Seams of Single-Ply Roofing Membranes: Pulse-Echo Ultrasonic Evaluation of a Prototype Test Apparatus," NISTIR 4424, National Institute of Standards and Technology, Gaithersburg, MD (October 1990).

[4] Watanabe, H. and Rossiter, W.J., Jr., "Effects of Adhesive Thickness, Open Time, and Surface Cleanness on the Peel Strength of Adhesive-Bonded Seams of EPDM Rubber Roofing Membrane," Roofing Research and Standards Development: 2nd Volume, ASTM STP 1088, American Society for Testing and Materials, Philadelphia, PA (1990).

[5] Rossiter, Walter J., Jr., Seiler, J.F., and Stutzman, P.E., "Report of Roof Inspection: Characterization of NewlyFabricated Adhesive-Bonded Seams at an Army Facility," NISTIR 89-4155, National Institute of Standards and Technology, Gaithersburg, MD (October 1989).

[6] Rossiter, Walter J., Jr., Seiler, J.F. and Stutzman, P.E., "Field Testing of Adhesive-Bonded Seams of Single-Ply Membranes," Proceedings, 9th Conference on Roofing Technology, National Roofing Contractors Association, Rosemont, IL (May 1989), pp. 78-87.

[7] Martin J.W., Embree, E., Rossiter W.J., Jr., "Effect of Contamination Level on strength of Butyl-Adhered EPDM Joints in EPDM Single-Ply Roofing Membranes," ibid., pp. 64-72.

[8] Hartmann, B. and Jarzynski, J., "Immersion Apparatus for Ultrasonic Measurements in Polymers," Journal of Acoustic Society of America, Vol. 56, No. 5 (November 1974).

[9] Krautkramer, J. and Krautkramer, H., "Ultrasonic Testing of Materials," Second Edition, Springer-Verlag, New York (1977), pp. 22-25.

[10] Rosenfield, M.J., "Field Test Results of Experimental EPDM and PUF Roofing," Technical Report M-357, US Army Corps of Engineers (September 1984). 
Table 1. Summary of roofs investigated ${ }^{a}$

\begin{tabular}{|c|c|c|c|c|}
\hline $\begin{array}{l}\text { Roof } \\
\text { No. }\end{array}$ & Location & $\begin{array}{c}\text { Adhesive } \\
\text { Type }\end{array}$ & $\begin{array}{l}\text { Attachment to } \\
\text { the substrate }\end{array}$ & Seam Age \\
\hline 1 & VA & Neoprene & Fully-adhered & Minimum of 5 years \\
\hline $2^{b}$ & IA & Butyl & Fully-adhered & About 4 years \\
\hline 3 & VA & Butyl & Fully-adhered & $\begin{array}{l}\text { A few minutes to } 9 \\
\text { days }\end{array}$ \\
\hline 4 & MD & Neoprene & $\begin{array}{l}\text { Mechanically } \\
\text {-fastened }\end{array}$ & About 4 years \\
\hline 5 & $\mathrm{VA}$ & Butyl & Fully-adhered & About 1 year \\
\hline
\end{tabular}


Table 2. Tests conducted on the laboratory-cured specimens

Test

Method

Pulse-echo

Average

Adhesive

Mass

Average

Adhesive

Thickness
Procedure

Tests were conducted using the transducer holder set on the seam, as described previously [3].

For most tests, measurements were made at five locations marked on each seam specimen. For the other cases, three measurements were made. Data reported are averages which had coefficients of variation of $9 \%$ or less.

The mass of each sheet used to prepare the seam specimens was determined before application of the adhesive using a balance sensitive to $0.01 \mathrm{~g}$. After bond formation, the mass of the seam specimen was determined. The average adhesive mass was calculated by subtracting the masses of the sheets from the specimen mass. It was assumed in this test that any losses in mass observed over time were associated with a loss of solvent present when the adhesive was applied to the rubber.

The average thickness of each sheet used to prepare the seam specimens was determined before application of the adhesive by making measurements at five points using a dial-faced thickness gage. After bond formation, the average thickness of the seam specimen was determined by repeating the measurements at the same five points. The thickness of the adhesive was calculated by subtracting the thicknesses of the sheets from the specimen thickness. Previous tests have indicated that this procedure provides average thickness values with a range of $10 \%$ of the mean adhesive thickness [4]. 
Table 3. Seam samples and cure conditions

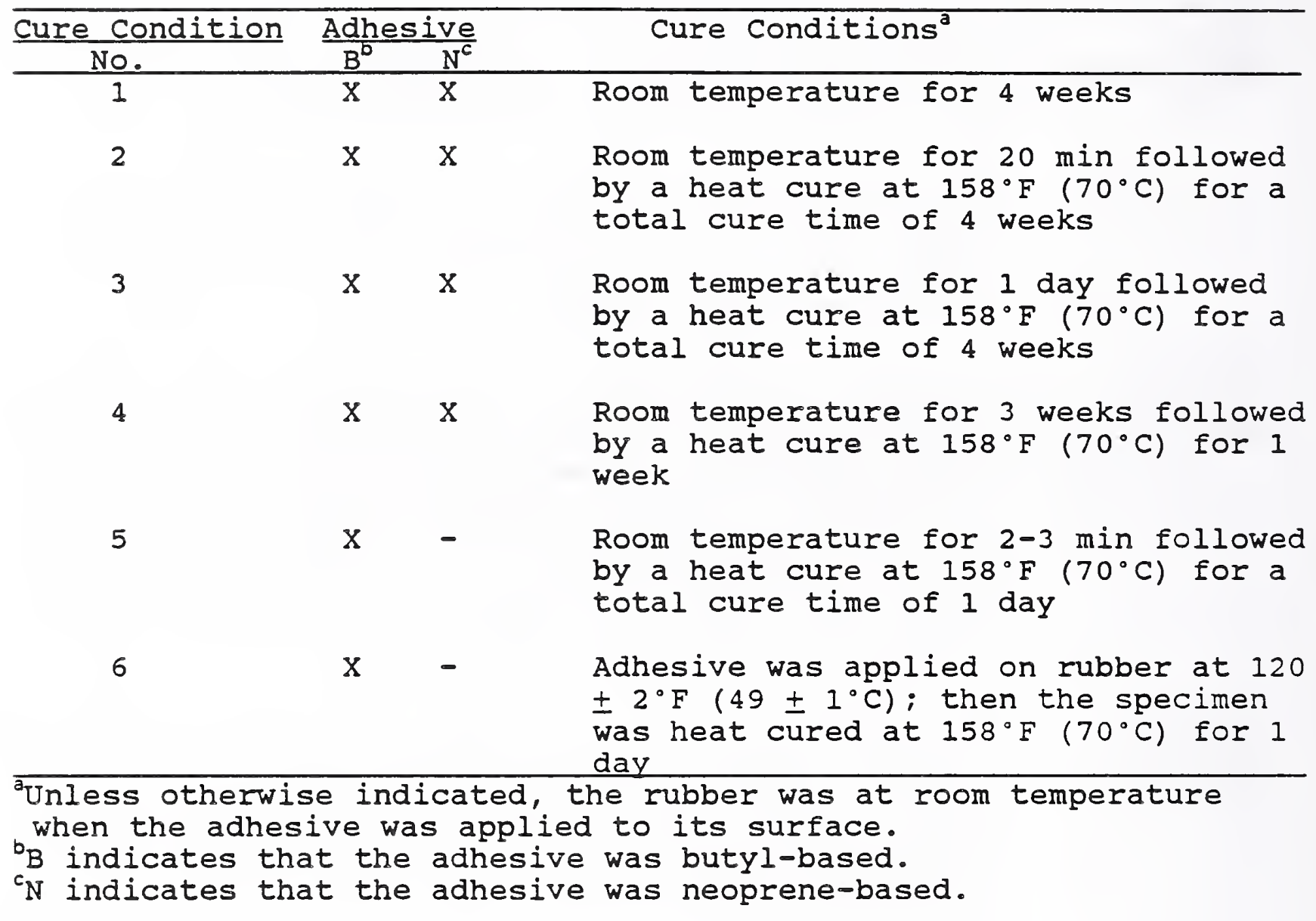




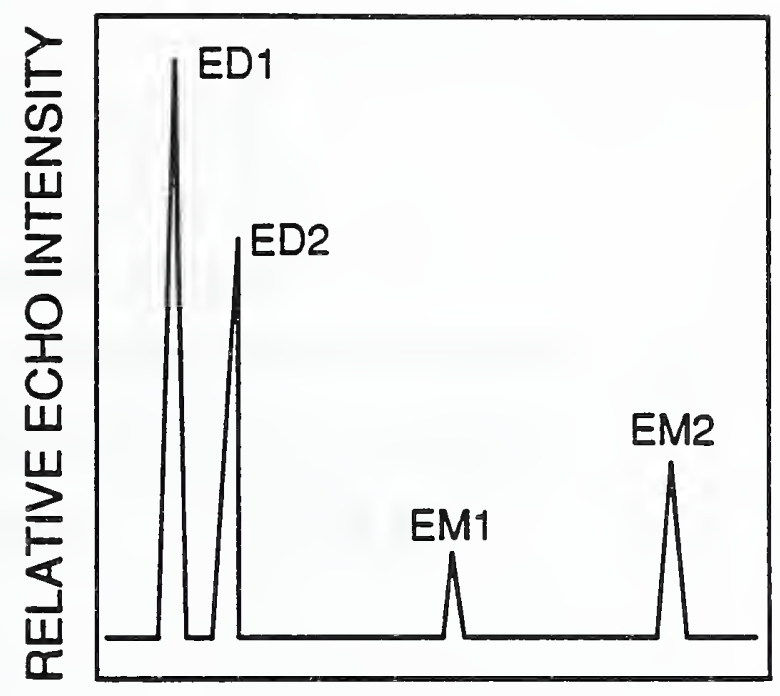

RELATIVE TIME

a. Well-Bonded Section

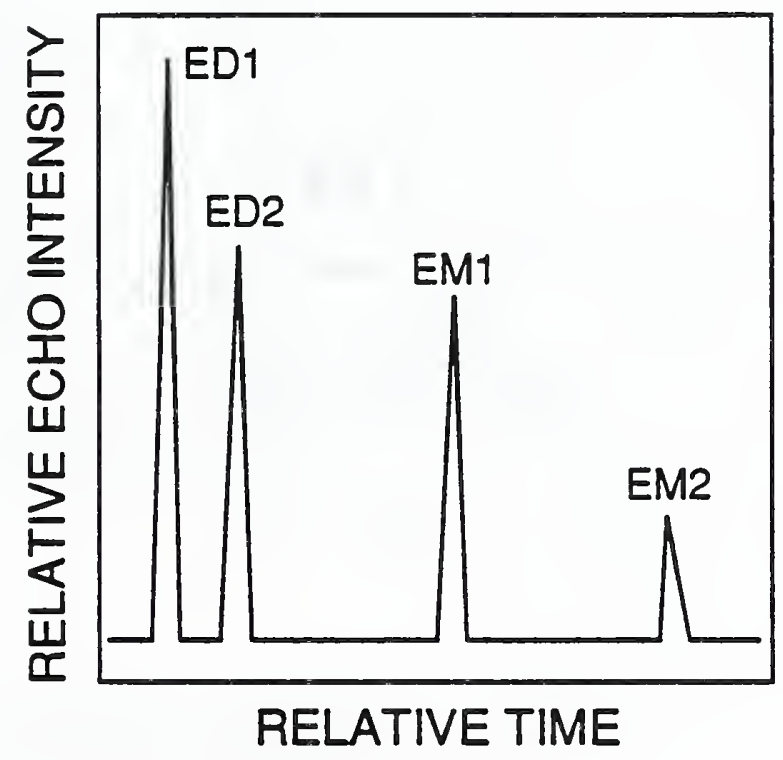

b. Section with a Void

Figure 1. Schematic illustration of echo patterns for a wellbonded section of a seam and a seam section with a void. (For the definition of the echoes, ED1, ED2, EM1, and EM2, see section 2.2.) 


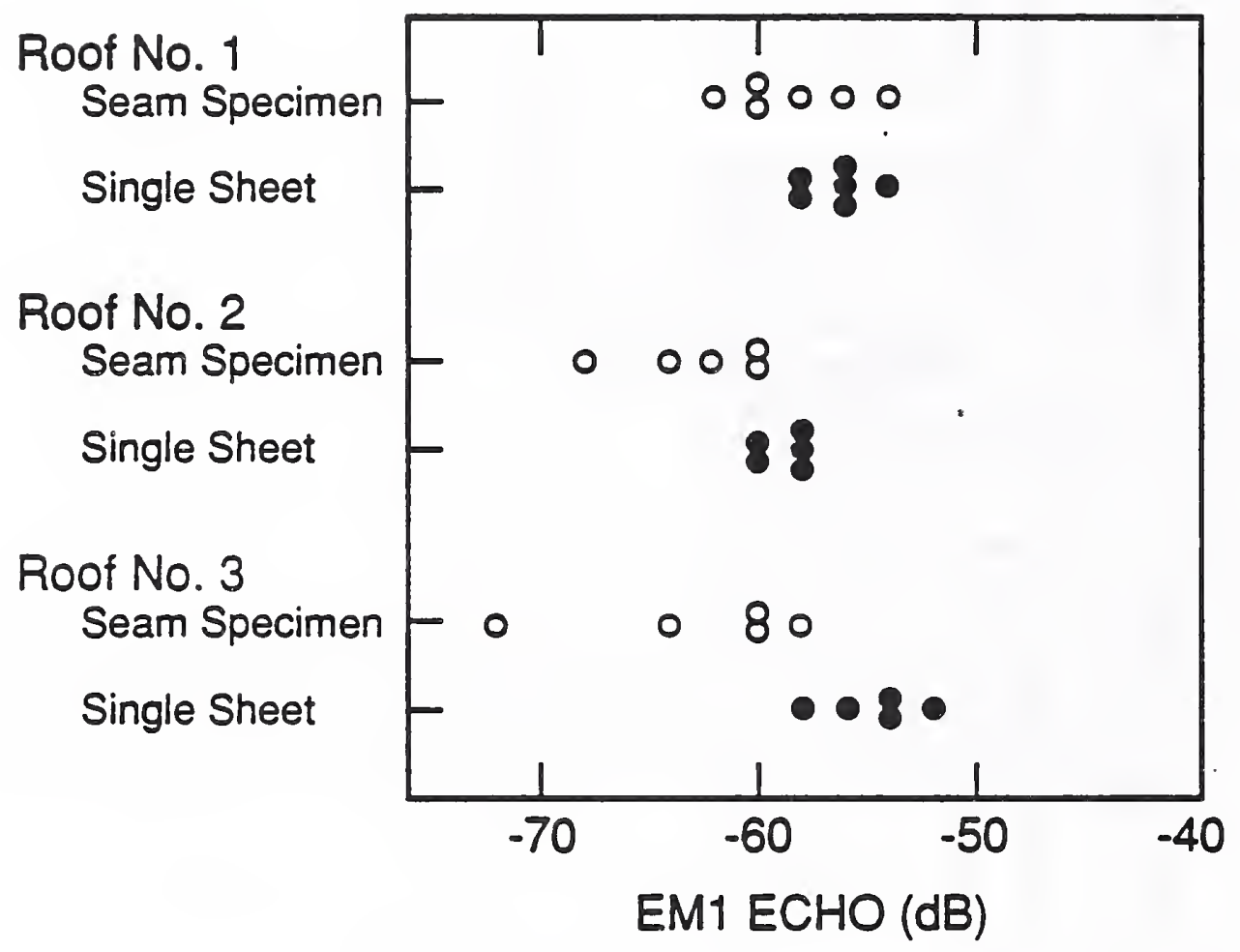

Figure 2. Intensity of EMI echoes measured for seam specimens and single sheets cut from roofs nos. $1-3$. (A $5-\mathrm{MHz}$ focusing transducer was used in the measurements.) 


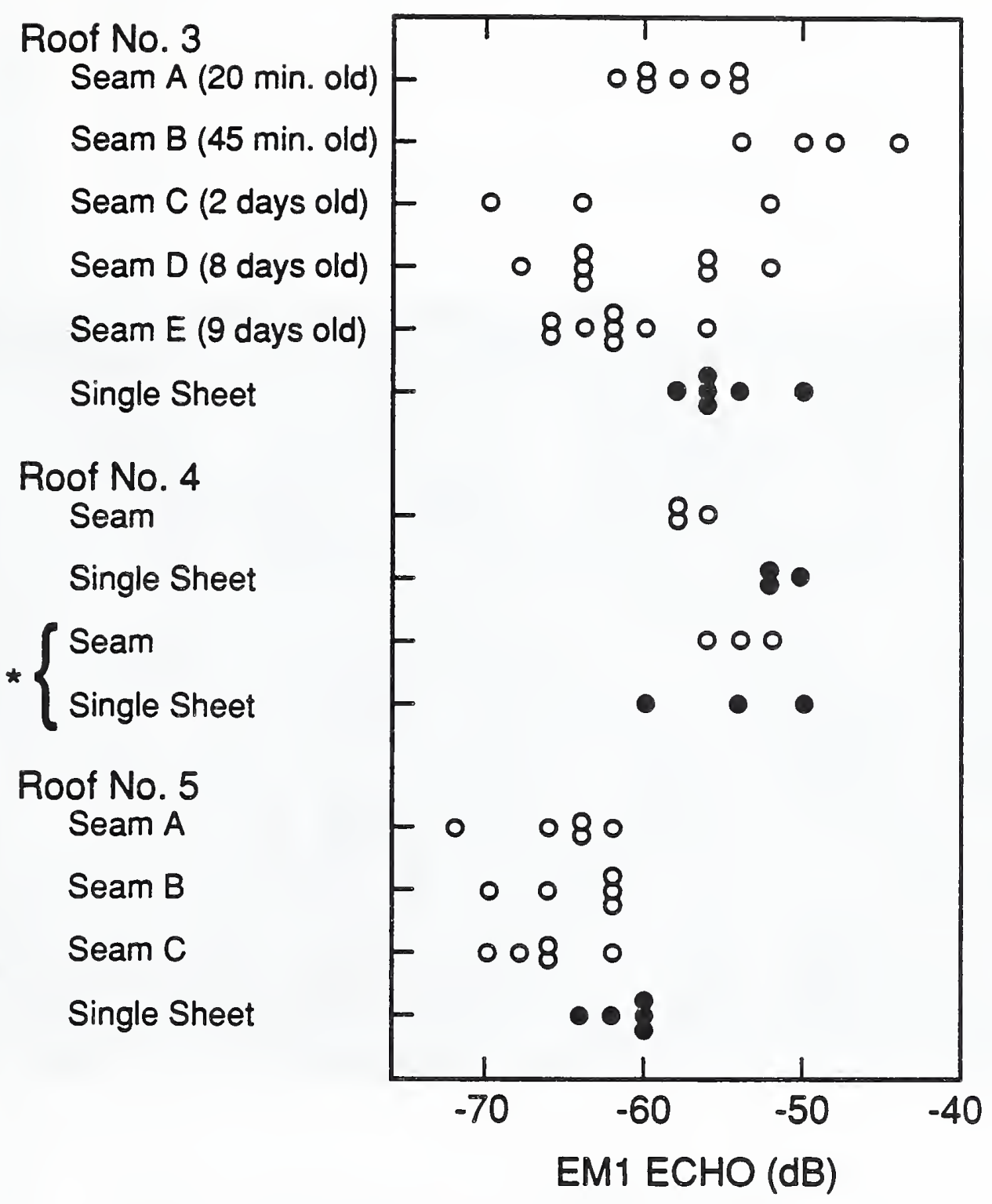

"Results obtained using 5-MHz non-focusing transducer for comparison

Figure 3. Intensity of EMI echoes measured in the field investigation for roof nos. 3-5. (Except where noted, a 5-MHz focusing transducer was used in the measurements.) 


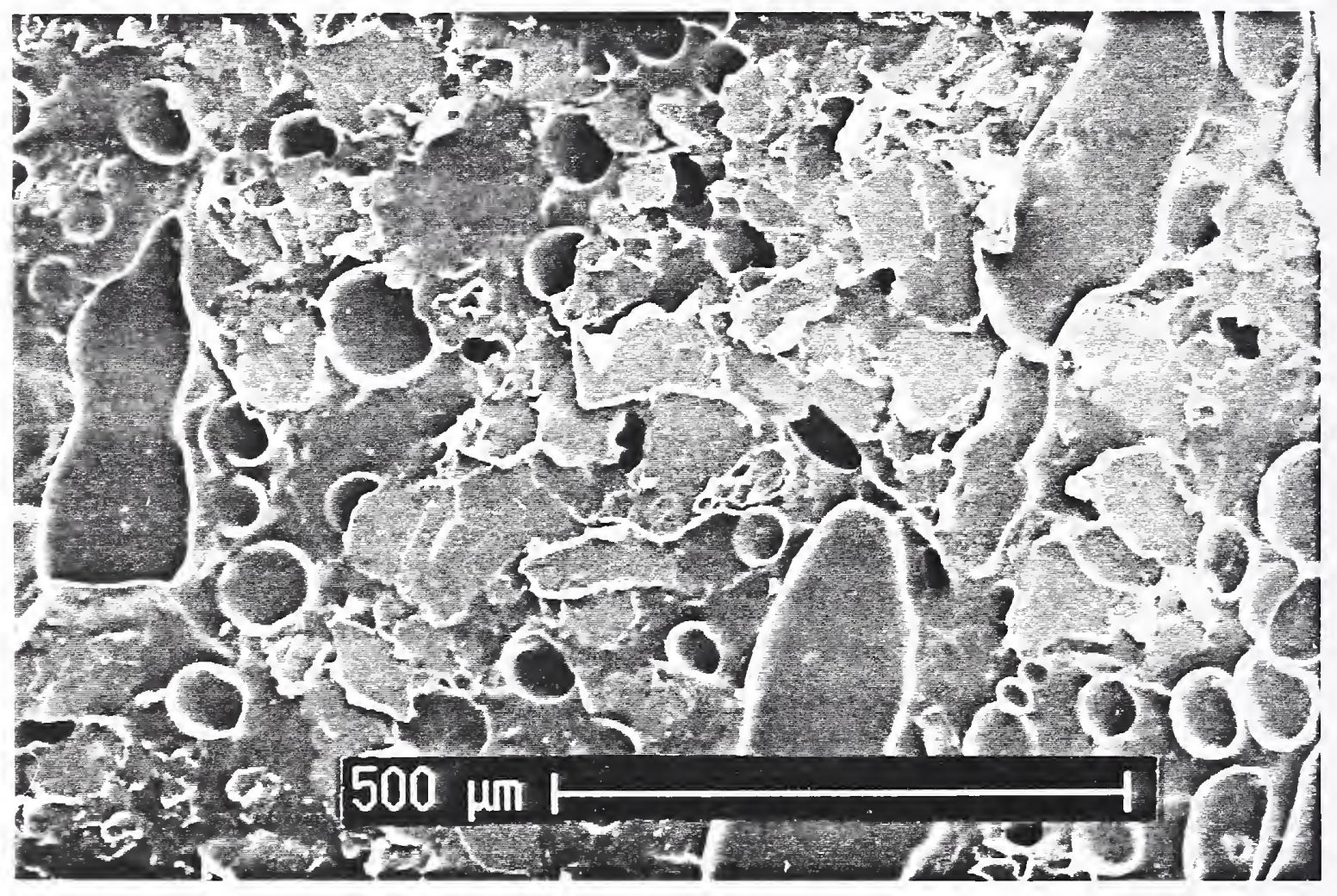

Figure 4. SEM photomicrograph of the ruptured surface of the adhesive layer in seam $A$ of roof no. 3. 


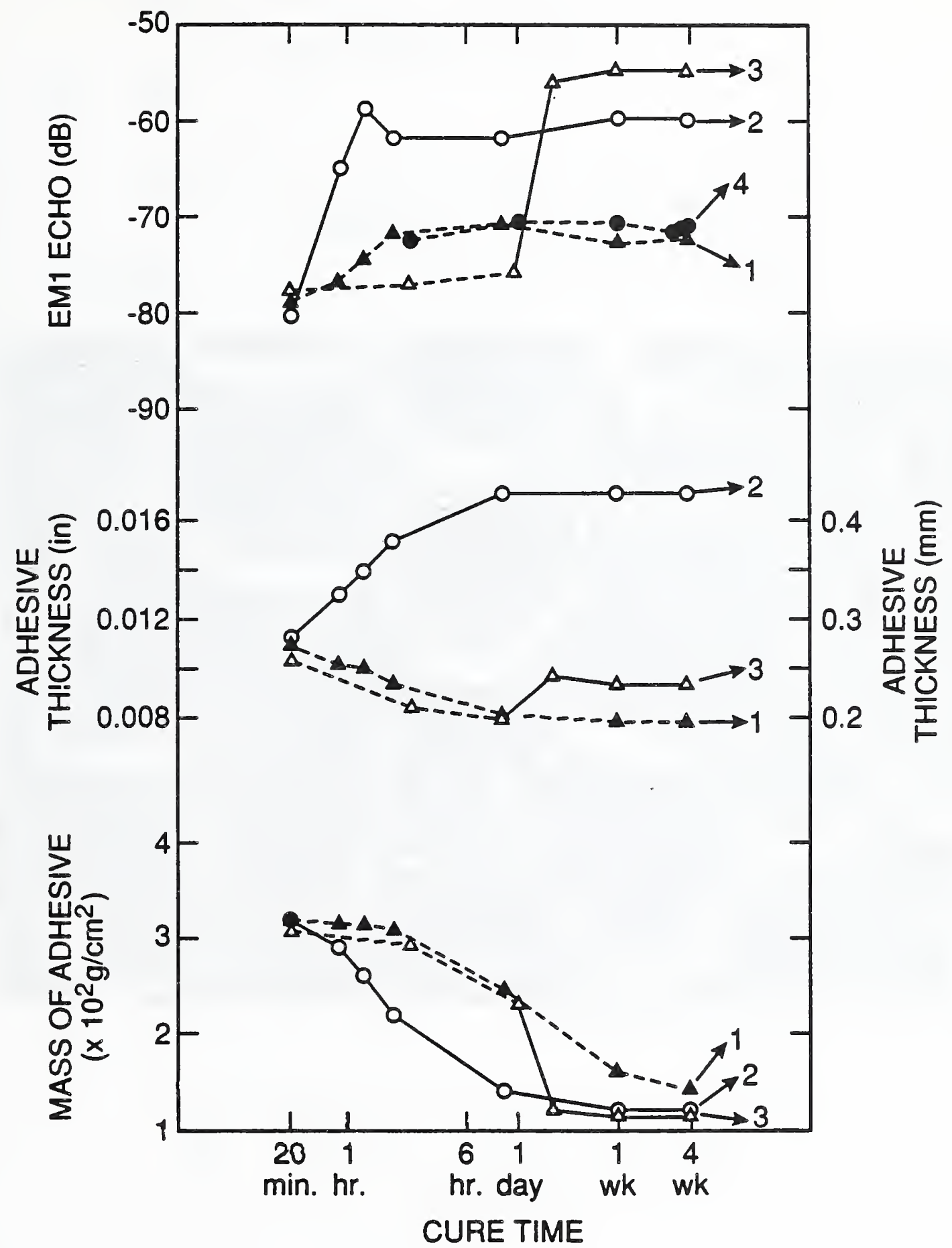

Figure 5. Results of the laboratory experiment on elevated cure temperature for seam specimens fabricated with a neoprene-based adhesive. (The numbers adjacent to the curves indicate the cure conditions given in Table 3.) 


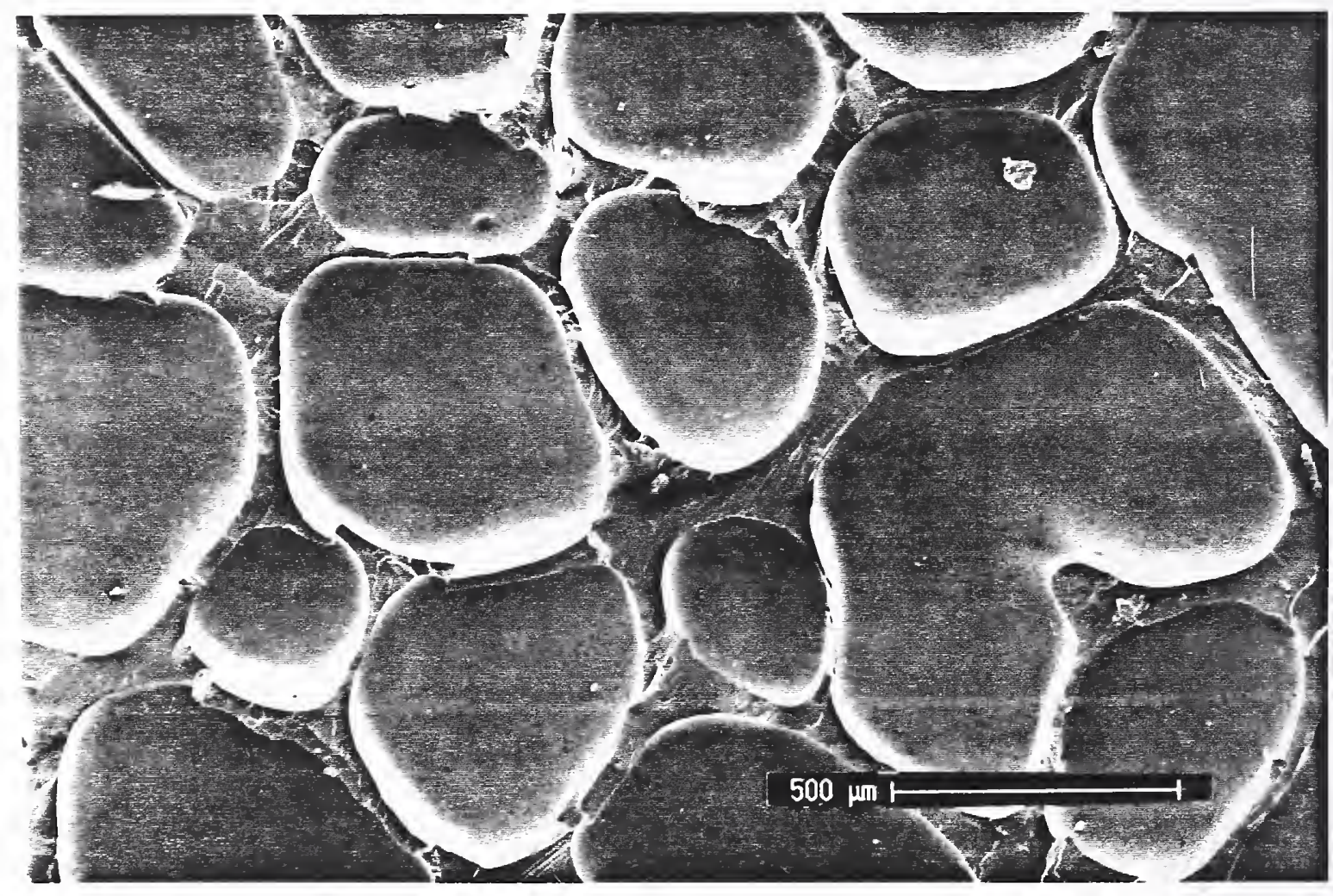

Figure 6. SEM photomicrograph of the ruptured surface of the neoprene-based adhesive layer. Micro-cavities are apparent. 


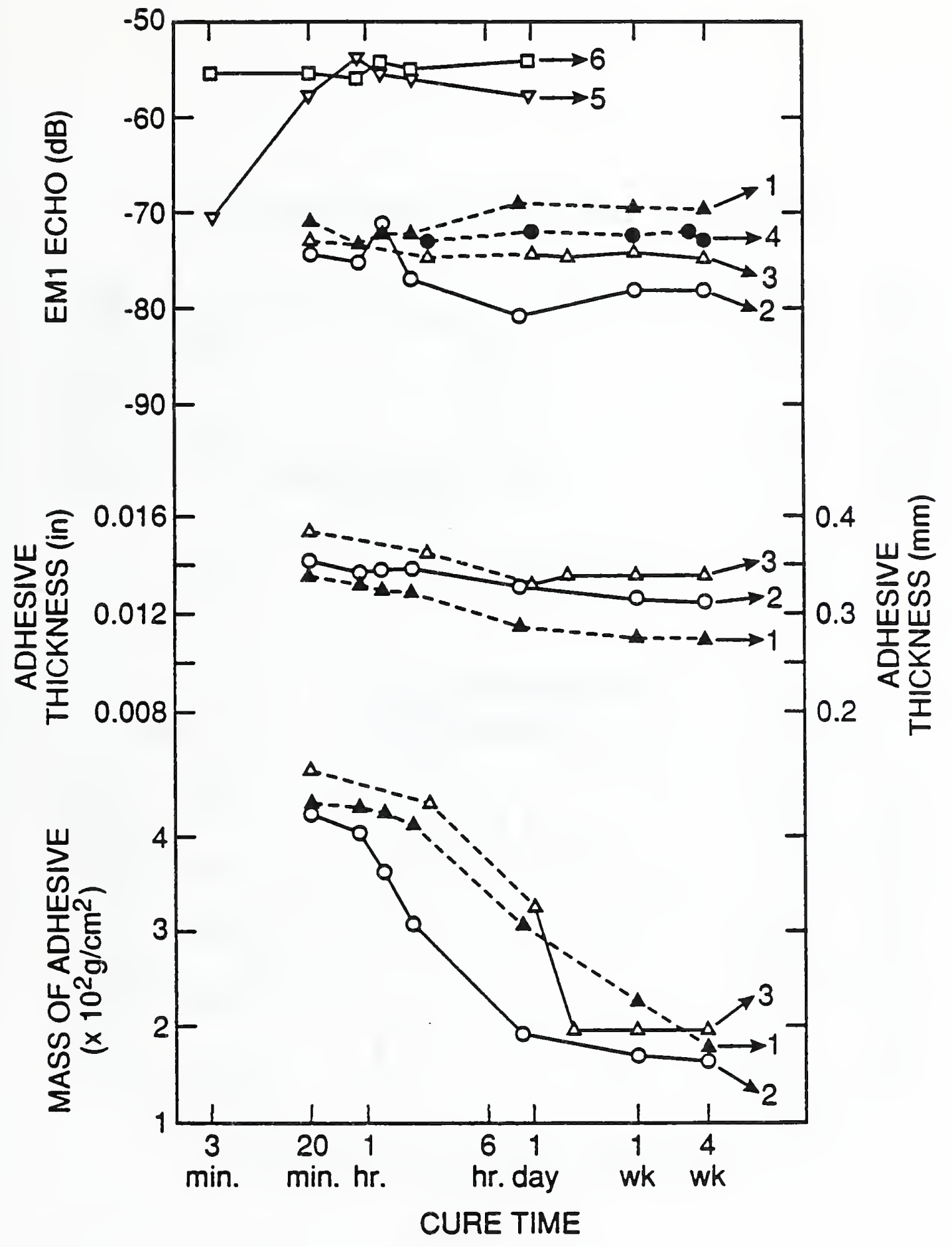

Figure 7. Results of the laboratory experiment on elevated cure temperature for seam specimens fabricated with a butylbased adhesive. (The numbers adjacent to the curves indicate the cure conditions given in Table 3.) 


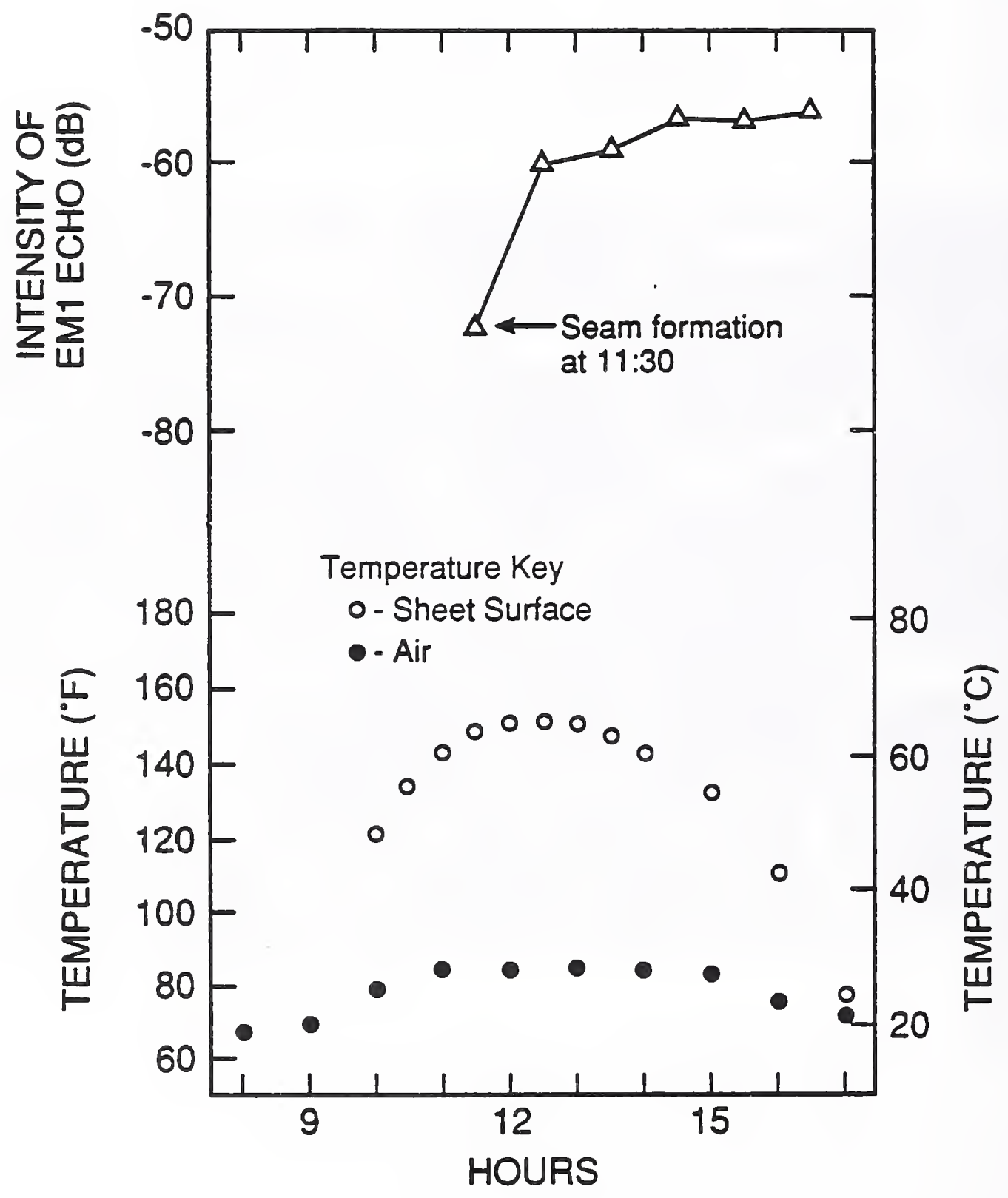

Figure 8. Temperatures and EMI echo intensity measured for the field seam specimen having a neoprene-based adhesive. 


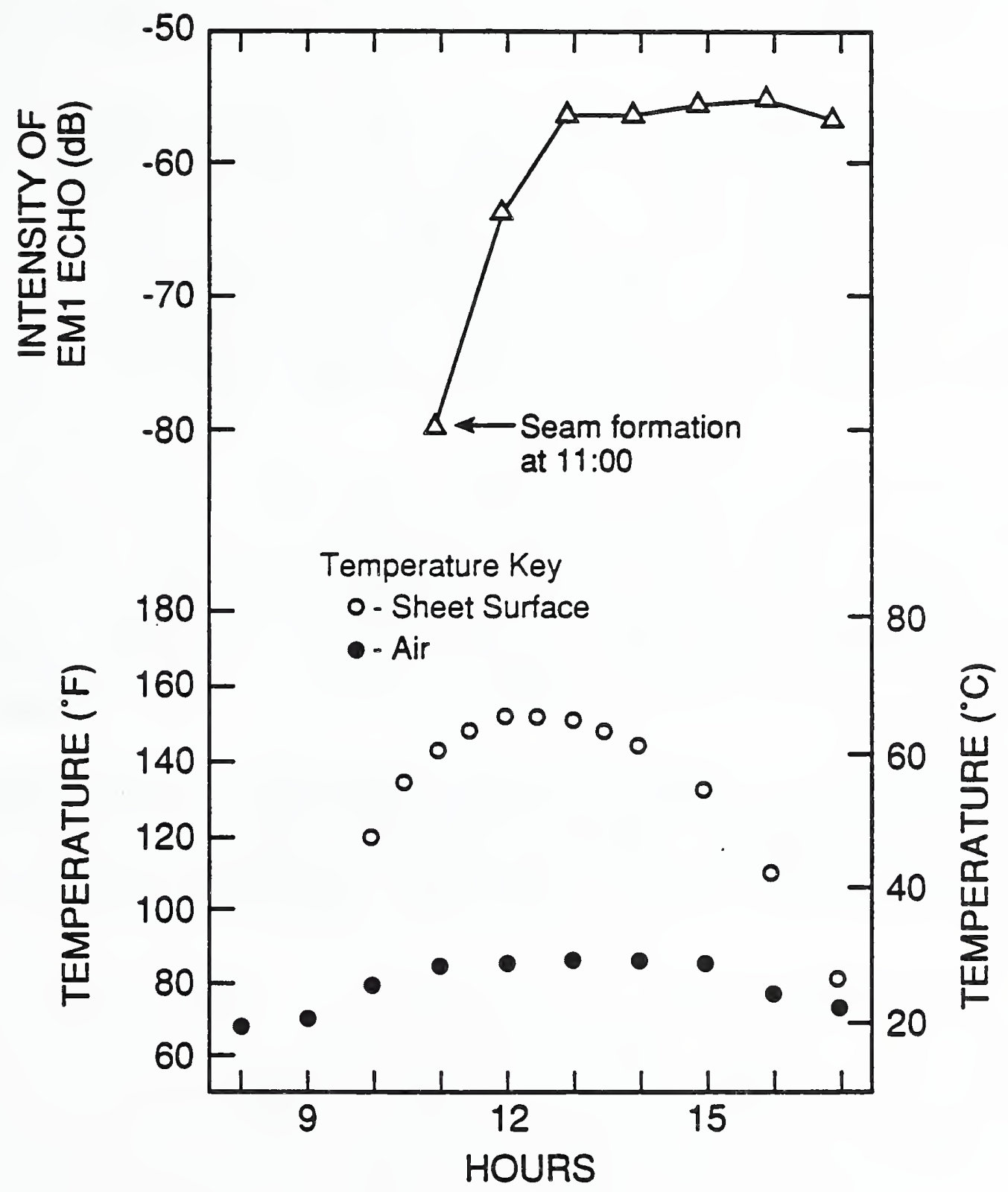

Figure 9. Temperatures and EMI echo intensity measured for the field seam specimen having a butyl-based adhesive. 


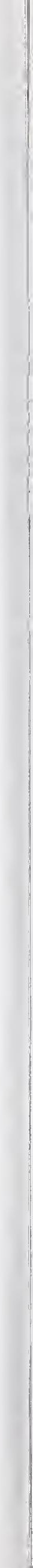


Figure Al shows a schematic of the field scanner. The basic components, typical of pulse-echo ultrasonic test equipment, are: the transducer (here incorporated in a holder), the pulser-receiver unit, and a couplant reservoir. The components are mounted on a wheeled luggage carrier to allow continuous scanning and maneuverability along lengths of seams in the field.

Figure A2 shows the technique to provide coupling of the transducer to the membrane surface. An immersible transducer was placed in a plastic cylindrical container having a height and diameter of 4 and 3.5 in. (102 and $89 \mathrm{~mm}$ ), respectively. The transducers selected in Phase 1 of the study were $5-\mathrm{MHz}$ focusing and $5-\mathrm{MHz}$ non-focusing types [3]. The distance between the front surface of the immersible transducer and the top surface of the seam specimen was set at the optimum value for the transducer used, based on the results of the Phase 1 study. The transducer holder was filled with water which was added through a small port sealed with a threaded screw plug.

A flexible rubber (urethane) diaphragm, having a thickness of 0.03 in. $(0.8 \mathrm{~mm})$, was used as the bottom of the holder. A flexible bottom was selected to provide a conformable surface and, thus, help to keep continuous contact of the holder with irregular (i.e., uneven or non-planar) surfaces of the field seam specimens. When the holder was filled with water, the diaphragm bulged slightly, which also helped to maintain contact with the surfaces of test specimens.

Water containing a laboratory detergent was used to couple the diaphragm and the seam surface acoustically. The rubber of the diaphragm was selected to have an acoustic impedance similar to that of water to minimize reflection of the ultrasonic echo at water-diaphragm interfaces, and also to have minimum attenuation of the signal passing through the diaphragm.

The transducer holder is attached to a plate at the bottom of the luggage carrier with a spring mechanism that allows for adjustment of the height of the holder above the roof surface. The couplant, whose flow can be adjusted using a plastic valve on the reservoir, is supplied to the seam in front of the transducer holder through a paint-brush pad. This brush pad is intended to drag across the seam surface during scanning to increase wetting of the surface with the couplant and to wipe away coarse particles. 
The field scanner was fabricated by $\mathrm{EMCO}^{4}$. The pulser-receiver unit was model no. DSL104 from Panametrics. It has an oscilloscope for detecting echoes and is compatible with transducers with nominal frequencies ranging from 1 to $10 \mathrm{MHz}$. The unit contains a rechargeable battery which may operate for eight hours, although it may also be directly connected to normal AC house lines. The operating controls include coarse and fine gain switches for adjusting the intensity of received echoes displayed on the oscilloscope. The coarse gain control provides adjustments in 20 decibel (dB) increments as follows: $0,20,40,60$, and $80 \mathrm{~dB}$. The fine gain control allows adjustments in $2 \mathrm{~dB}$ increments from 0 to $20 \mathrm{~dB}$.

\footnotetext{
${ }^{4}$ Certain company names or products are mentioned in the text to specify adequately the experimental procedure and equipment used. In no case does such identification imply recommendation or endorsement by the National Institute of Standards and Technology, nor does it imply that the products are necessarily the best available for the purpose.
} 


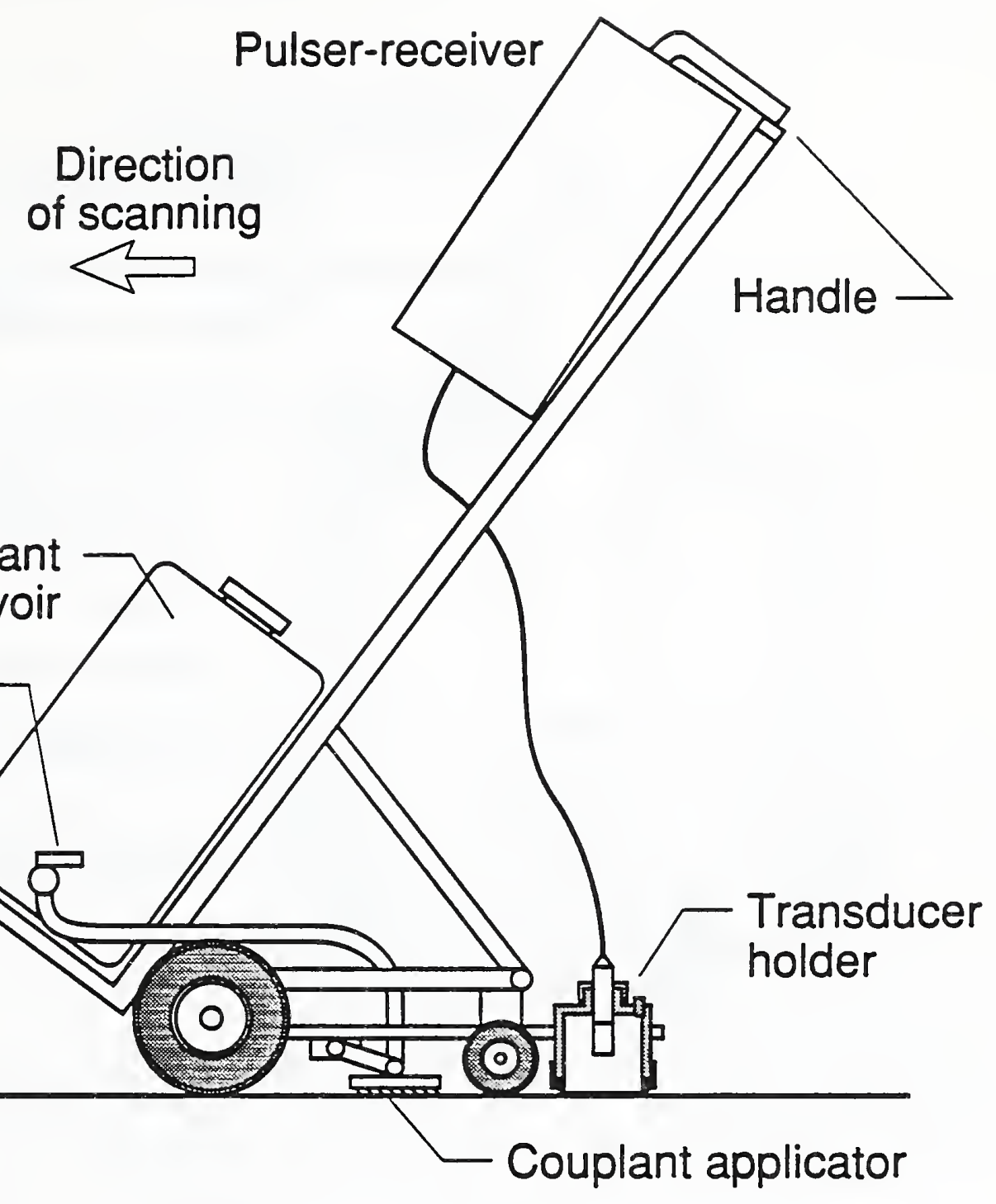

Figure A1. Prototype field scanner used in the study. (The detail of the transducer holder is presented in Figure A2.) 


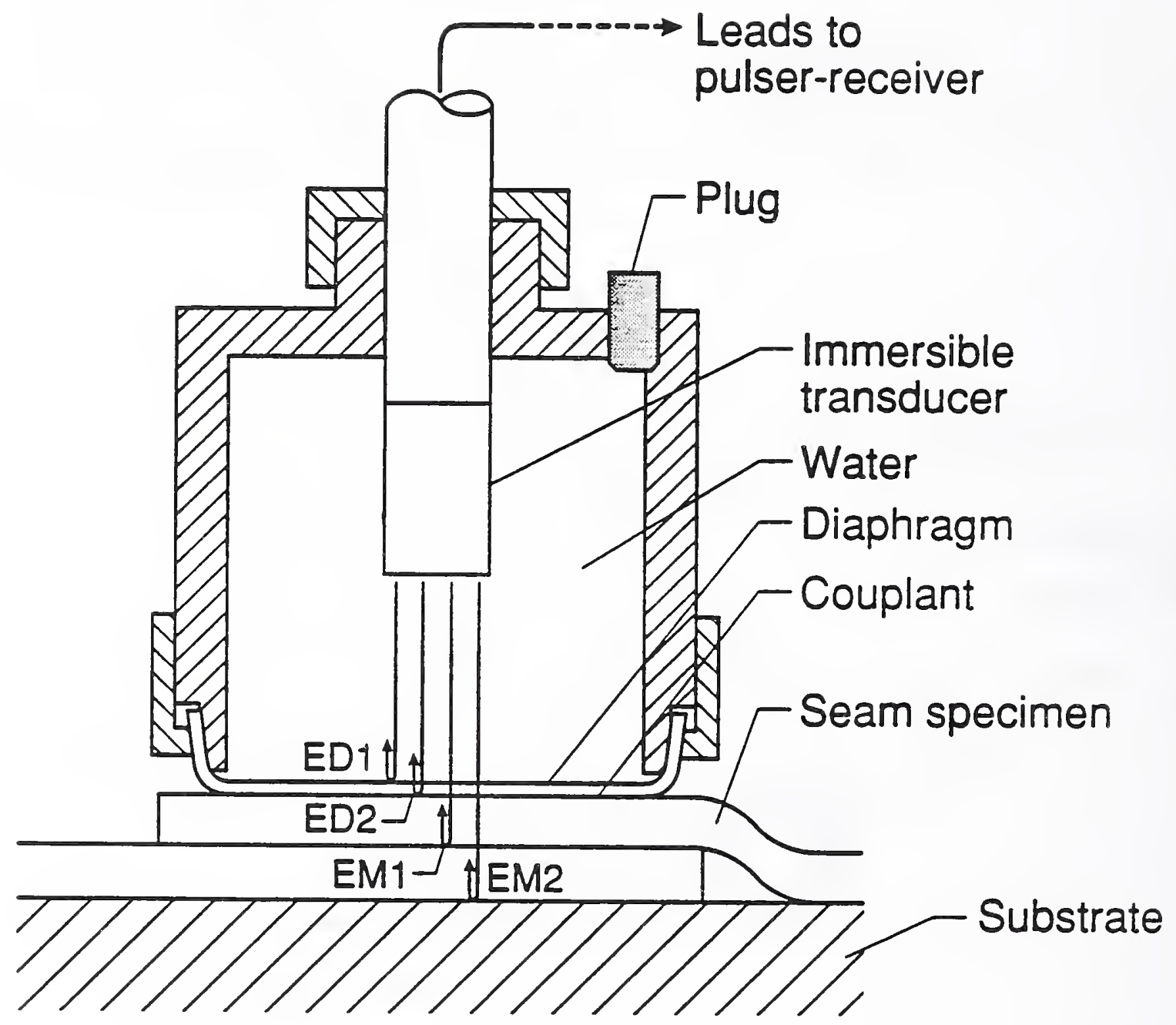

Figure A2. Schematic illustration of the transducer holder acoustically coupled to a seam specimen. (Reflections of the ultrasonic pulse from the various interfaces are also illustrated, and are designated as ED1, ED2, EM1, and EM2.) 


\section{BIBLIOGRAPHIC DATA SHEET}

$\begin{array}{r}\text { 2. PERFORMING ORGANIZATION REPOAT NUMBER } \\ \hline \begin{array}{r}\text { PUBUCATION DATE } \\ \text { NOVEMBER } 1990\end{array}\end{array}$

4. TITLE AND SUBTITLE

Pulse-Echo Ultrasonic Evaluation of the Integrity of Seams of Single-Ply Roofing Membranes: Results of Field Investigations and Recommendations

5. AUTHOR(S)

Hiroshi Watanabe and Walter J. Rossiter, Jr.

6. PERFORMINO ORGANIZATION (IF JOINT OR OTHER THAN MIST, SEE INSTRUCTIONS)

U.S. DEPARTMENT OF COMMEACE

NATIONAL INSTITUTE OF STANDARDS AND TECHNOLOOY

GAITHERSBURG, MD 20899

7. CONTRACT/GRANT NUMBER

8. TYPE OF REPORT AND PERIOD COVERED

9. SPONSORING ORGANIZATION NAME AND COMPLETE ADDRESS (STREET, CITY, STATE, ZIP)

Naval Civil Engineering Laboratory

Port Hueneme, CA 93043-5003

\section{SUPPLEMENTARY NOTES}

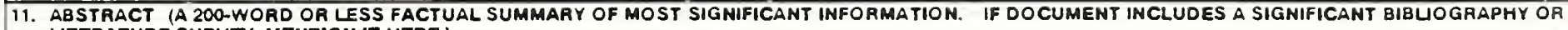
UTERATURE SURVEY, MENTION IT HERE.)

This report describes the second and final phase of a study to develop an ultrasonic NDE method for evaluating the integrity of seams of single-ply roofing membranes. The results of the laboratory evaluation of a prototype pulse-echo apparatus (the field scanner) were positive in that voids could be distinguished from well-bonded sections of the specimen using the intensity of the echo from the adhesive layer. In the Phase 2 study, seams of existing EPDM single-ply membranes were examined by roof-top scanning to evaluate the performance of the field scanner in practice. This was followed by laboratory tests to confirm and explain observations made during the field tests of the seams. The field scanner was sensitive to micro-cavities, which could be generated in adhesive layers. This resulted in a number of "false positive" readings. The formation of the micro-cavities was attributed to the temperature-induced volatilization of residual solvent remaining in the adhesive layer after its application on the membrane material. It was concluded that the field scanner technique had limited applicability for assessing the condition of solvent-adhesive seams because it could not readily differentiate between the micro-cavities and voids and delaminations in the adhesive layer. The results also implied that the field scanner might be applicable to seams formed using other teehniques and that the addition of data recording and processing equipment would enhance the operator's ability to interpret the pulse-echo data obtained.

12. KEY WORDS (6 TO 12 ENTRIES; ALPHABETICAL ORDER; CAPITALIZE ONLY PROPEA NAMES; AND SEPARATE KEY WOADS BY SEMICOLONS)

adhesive-bonding; EPDM rubber; field inspection; membranes; nondestructive testing; pulse-echo method; roofing; seams; ultrasonics; voids

FOR OFFICIAL DISTRIBUTION. DO NOT RELEASE TO NATIONAL TECHMICAL INFORMATION SERVICE (NTIS).

ORDER FROM SUPERINTENDENT OF DOCUMENTS, U.S. GOVERMMENT PRINTING OFFICE, 


